\title{
Ontogênese de caneluras em pedúnculo de flores de laranjeira doce infectados pelo vírus da tristeza dos citros estirpe "Capão Bonito"
}

\author{
Francisco André Ossamu Tanaka ${ }^{1,4}$; Elliot Watanabe Kitajima ${ }^{1}$; Marcos Antonio Machado² ; Sílvia Rodrigues \\ Machado ${ }^{3}$
}

${ }^{1}$ Laboratório de Microscopia Eletrônica (NAP/MEPA-ESALQ/USP), Av. Pádua Dias, 11; CEP 13400-900, Piracicaba, SP., ewkitaji@ esalq.usp.br; ${ }^{2}$ Centro APTA Citros Sylvio Moreira, Rodovia Anhangüera km 158, Caixa postal 04, CEP 13490-970, Cordeirópolis, SP. ${ }^{3}$ Departamento de Botânica, Instituto de Biociências, UNESP, Botucatu, SP. ${ }^{4}$ Bolsista FAPESP; Parte de Tese de Doutorado do primeiro autor, vinculada ao programa de Pós-Graduação em Ciências Biológicas (Botânica), UNESP, Campus de Botucatu.

Autor para correspondência: Francisco André Ossamu Tanaka (fatanaka@esalq.usp.br)

Data de chegada: 10/07/2007. Aceito para publicação em: 12/02/2009.

\section{RESUMO}

Tanaka, F.A.O.; Kitajima, E.W.; Machado, M.A.; Machado, S.R.. Ontogênese de caneluras em pedúnculo de flores de laranjeira doce infectados pelo vírus da tristeza dos citros estirpe "Capão Bonito". Summa Phytopathologica, v.35, n.4, p.316-321, 2009

Um estudo da ontogênese das caneluras induzidas em ramos de laranjeiras doces suscetíveis por isolados severos do vírus da tristeza dos citros (Citrus tristeza vírus - CTV) foi feito usando-se como modelo pedúnculos florais e de frutos. O menor calibre destes órgãos permite um melhor acompanhamento do processo. As observações foram feitas em laranjeira cv. Pêra infetada pelo isolado severo Capão Bonito do CTV. Cinco fases do processo de formação de caneluras puderam ser deduzidas pelas análises anatômicas. As primeiras alterações são representadas pelo aparecimento de células adensadas, hipertrofia e hiperplasia no parênquima e câmbio do floema e uma desorganização generalizada desta área. Segue-se uma atividade intensa do câmbio do floema adjacente e sua expansão em direção ao xilema. Esta invasão do xilema resulta na ruptura do anel do xilema pela massa celular do floema constituída de células recém formadas de parede celular delgada. Esta invasão do floema em direção ao xilema inicia um processo de degeneração dos vasos e parênquima do xilema. Finalmente há um colapso completo da região do xilema invadida, que é substituída pela massa do floema, resultando na canelura, notada ao se remover a casca.

Palavras-chave adicionais: anatomia vegetal, Citrus sinensis, microscopia eletrônica de transmissão.

\begin{abstract}
Tanaka, F.A.O.; Kitajima, E.W.; Machado, M.A.; Machado, S.R..Ontogenesis of the stem pitting in the floral and fruit peduncle of sweet orange cv. Pêra infected by the Capão Bonito isolate of the Citrus tristeza virus. Summa Phytopathologica, v.35, n.4, p.316-321, 2009

An ontogenetic study of the stem pitting was carried out, using as a model system the peduncle of flowers and fruits of sweet orange cv. Pêra infected by a very severe isolate, Capão Bonito, of Citrus tristeza virus (CTV). Anatomical and ultrastructural analysis revealed five phases of this process. It starts with the localized appearance of chromatic cells in the phloem parenchyma, hypertrophy of companion and cambial cells and overall disorganization of the phloem and deposition of a dense material. The next step is characterized by the invasion of the xylem by an abnormal mass of phloem

parenchymal cells formed by the disorganized proliferation. These changes lead to the third phase, where xylem ring is interrupted by the invading abnormal phloem proliferation, which produces undifferentiated cells with thin cell wall. The irregular activity of the vascular cambium continues followed by the complete degeneration of the xylem complemented by the appearance of dense phenolic deposits. Finally, there is the complete collapse of the xylem in the invaded region, and the corresponding space is occupied by the phloem mass which correspond to the stem pitting.
\end{abstract}

Keywords: plant anatomy, Citrus sinensis, transmission electron microscopy

A tristeza dos citros foi introduzida na América do Sul via Argentina na década dos 1930 chegando ao Brasil uma década depois $(2,3,4,17)$, sendo rapidamente disseminada de maneira semi-persistente pelo afídeo vetor Toxoptera citricidus Kirk. $(14,15)$ além de borbulhas $(7,1)$. No Brasil dizimou cerca de 10 milhões de laranjeiras doces (Citrus sinensis (L.) Osbeck) enxertadas sobre laranjeira azeda (C. aurantium L.). A doença é causada pelo vírus da tristeza dos citros (Citrus tristeza vírus - CTV) do gênero Closterovirus $(5,26)$, cujas partículas são delgadas, extremamente longas e flexuosa (10-12 nm x $2.000 \mathrm{~nm})(11)$. No Brasil CTV acha-se sob controle pelo uso de porta-enxertos tolerantes como limoeiro Cravo, tangerineira e Poncirus trifoliata Raf. e seus híbridos, e também pela utilização em larga escala da premunização com estirpes fracas (17). O genoma do CTV é uma fita única de RNA de fita simples de $c a .19 .000 \mathrm{~kb}$, contendo 12 "open reading frames" e encapsidada por 2 proteínas (p25 e p27). Sabe-se que numa planta infetada ocorre um complexo de diferentes haplótipos do CTV de cuja composição dependeria a severidade dos sintomas (19).

O CTV infecta exclusivamente o tecido do floema. Massas fibrosas, formadas de vírions estão presentes em células companheiras do floema misturadas com vesículas. Ocorre também desintegração dos cloroplastos, com acúmulo de fitoferritina em seu interior e alterações 
nas mitocôndrias que contém frequentemente glóbulos osmiofílicos. Agregados de partículas podem ocorrer também nos vasos do floema, onde podem ser distinguidas das proteínas $\mathrm{P}$, por serem mais delgadas. Comumente nas proximidades destas células infetadas notam-se células companheiras, do parênquima do floema e elementos de tubo crivados completamente colapsados $(12,25,9)$.

O CTV infecta algumas outras rutáceas além do gênero Citrus havendo um registro de infecção experimental de Passiflora coerulea L. (17). Em combinação suscetível (laranjeira doce sobre laranjeira azeda) ocorrem folhas coriáceas e bronzeadas, amarelecimento de folhas velhas, 'die back', podridão das raízes e morte da planta. Certos isolados severos, como o Capão Bonito podem induzir depressões no lenho (caneluras= "stem pitting") em copas suscetíveis como a cv. Pêra, mesmo enxertados em cavalos tolerantes (17).

Estudos detalhados das alterações anatômicas da região vascular na região do enxerto têm dado suporte ao conceito de que em porta enxertos intolerantes, a infecção pelo CTV causa degeneração do floema na região do enxerto. Sucederiam atividades anormais na região cambial, seguida de hipertrofia e hiperplasia das células parenquimatosas do floema acompanhadas de degeneração e necrose $(16,21,22,23,24)$. Isto levaria ao bloqueio do fluxo de fotossintatos à raiz, causando sua podridão e consequiente morte da planta.

A anatomia das caneluras foi estudada em detalhe por Brlansky et al. (6) em ramos de laranjeira doce cv. Navel. Segundo estes autores as caneluras seriam causadas pela invasão do xilema pelas células do floema, em seguida à intensa atividade cambial do floema.

Uma das dificuldades neste tipo de estudo é que nos ramos a área englobada é relativamente grande dificultando a observação da sequiência dos eventos que gerariam as caneluras. Neste trabalho contornou-se esta dificuldade, utilizando como modelo o pedúnculo de flores e frutos, de laranjeira cv. Pêra, infetado por um isolado severo, Capão Bonito, do CTV logrando-se acompanhar a ontogênese das caneluras.

\section{MATERIAL E MÉTODOS}

\section{Amostragens}

Pedúnculos de flores e frutos em formação de laranjeiras cv. "Pêra" foram coletadas de um pomar experimental do Instituto Agronômico de Campinas, em Capão Bonito, SP. As plantas achavam-se naturalmente infetadas pela estirpe Capão Bonito do CTV e exibiam caneluras nos ramos e troncos. Como controle foram utilizadas materiais provenientes de plantas sadias, mantidas em condições de estufa, no Centro APTA Citros Sylvio Moreira em Cordeirópolis, SP.

Amostras da região mediana dos pedúnculos foram processadas em quatro diferentes fases de desenvolvimento: (I) Imediatamente após a antese; (II) Início da frutificação; (III) estádio intermediário de desenvolvimento dos frutos; (IV) na maturação dos frutos.

\section{Microscopia de luz}

Fragmentos dos pedúnculos foram fixados em solução de Karnovsky (10) modificado (glutaraldeído 2,5\%, paraformaldeído 2\% em tampão cacodilato $0,05 \mathrm{M}, \mathrm{pH} 7,2$ ) por no mínimo duas horas, desidratados em série de concentração crescente de etanol, infiltrados e emblocados em historesina (glicol metacrilato) JB-4 Polyscience, segundo protocolo de Ruetze \& Schmitt (20). Os blocos foram seccionados em micrótomo rotatório manual equipado com navalha de aço, com $5 \mathrm{~mm}$, coradas com solução ácida de azul de touluidina a $0,05 \%, \mathrm{pH} 3,2$ (8) e montadas em resina "Entellan". Os exames foram efetuados em um fotomicroscópio de luz Zeiss MC 80.

\section{Microscopia eletrônica de transmissão (MET)}

Para estudos ultraestruturais, parte das amostras fixadas em solução de Karnovsky foi pós-fixada em $\mathrm{OsO}_{4}, 1 \%$, no mesmo tampão, por uma hora, desidratada em série de concentração crescente de acetona, infiltrada e emblocada em resina epóxica de baixa viscosidade Spurr. Secções ultrafinas destes blocos foram obtidas em um ultramicrótomo Leica UC6, equipado com navalha de diamante, montadas em telinhas de cobre de 200 mesh, cobertas com película de Formvar e contrastadas com acetato de uranila a $3 \%$ e citrato de chumbo (13). Os exames das secções foram feitos em um microscópio eletrônico de transmissão Zeiss EM 900.

\section{RESULTADOS}

\section{Microscopia de luz}

Exames das secções transversais de pedúnculos de flores e frutos permitiram observar alterações localizadas no floema e que resultariam, pela sua evolução, nas caneluras.

As primeiras alterações notadas no pedúnculo foram: adensamento de células companheiras dos vasos crivados, correspondentes às células cromáticas de Schneider et al. (23); hipertrofia, adensamento e degeneração/necrose de muitas células do parênquima do floema (Fig. 1). Estas alterações são seguidas por uma intensa proliferação do parênquima do floema no câmbio que pressiona o tecido do xilema no lenho, iniciando uma invasão. No conjunto de células do floema notase degeneração dos vasos (Fig. 2). O processo de invasão do xilema acentua-se ocorrendo a interrupção do anel do xilema (Fig. 3). Seguese atividade cambial irregular na região do floema e aprofundamento da invasão do xilema (Fig. 4), e a má formação e degeneração dos vasos do xilema na região invadida (Fig. 5).

\section{Microscopia eletrônica de transmissão (MET)}

Áreas correspondentes às observadas ao microscópio de luz puderam ser detectadas também por MET. Na fase inicial, não há alterações ultraestruturais marcantes, mas notam-se algumas células do parênquima do floema mais adensadas (Fig. 6). Algumas das células companheiras adensadas, referidas como células cromáticas, continham massas de vírions do CTV (Fig. 8). Outras, contudo, se adensam completamente, provavelmente devido a acúmulo de material fenólico (Fig. 7) e freqüentemente terminam por se colapsarem devido à hiperplasia do parênquima adjacente. O processo de compressão faz com que os vasos crivados de contorno circular, se tornem poligonais, tendo junto as células cromáticas (Fig. 8). No câmbio, a intensa proliferação resulta na compressão de vasos crivados alterados e adensados (Fig. 9). Detalhes do conjunto de células do floema que invade o xilema mostram que muitas das células do floema em contato com os vasos do xilema estão se colapsando e o mesmo ocorre nos vasos do xilema adjacente (Figs. 10, 11).

\section{DISCUSSÃO}

A escolha do modelo do pedúnculo de flores e de frutos em formação mostrou-se adequado para acompanhar a ontogênese de caneluras induzidas nos ramos e troncos de laranjeiras infetadas por estirpes severas do CTV. Anatomicamente o pedúnculo é similar aos ramos e tendo menor calibre torna-se um sistema mais fácil de acompanhar as 


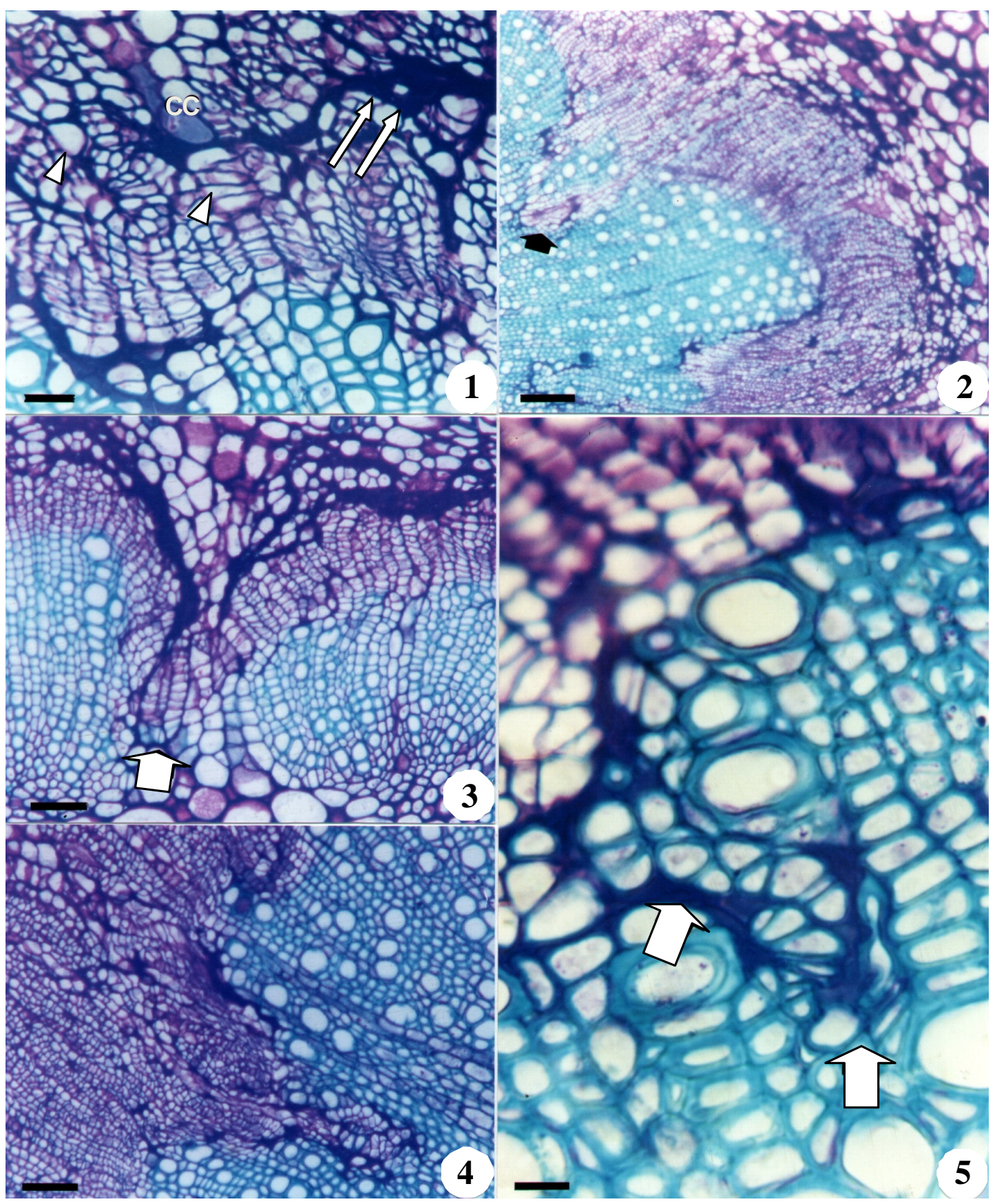

Figuras 1-5. Micrografia de luz de secções transversais de pedúnculos florais e de frutos de laranjeira doce (Citrus sinensis) cv. 'Pera', mostrando as fases sucessivas da formação de caneluras ("pitting") conseqüentes à infecção em campo com o vírus da tristeza dos Citros (Citrus tristeza vírus - CTV), isolado Capão Bonito. 1. Fase inicial; começo da desorganização do floema com ocorrência de células cromáticas (CC) e células hipertrofiadas (setas grossas). Parte do tecido acha-se necrosado (setas finas) (barra $=23 \mu \mathrm{m}$ ). 2. Ilustração de uma segunda fase, onde se inicia a invasão da região do xilema pelo tecido hiperplasiado do câmbio e floema (seta) (barra $=90 \mu \mathrm{m}$ ). 3 e 4 . Interrupção do anel do xilema (seta) como conseqüência desta invasão pela proliferação celular do floema e do câmbio (barra $=45 \mu \mathrm{m}$ ). 5. Detalhe da degeneração dos elementos dos vasos do xilema, nas adjacências da área invadida pelas células proliferadas do floema e do câmbio, resultando no colapso total da região e a conseqüente formação da canelura (barra $=12 \mu$ m).

sucessivas alterações tissulares decorrente da formação de caneluras em cultivares suscetíveis de laranjeiras, como a 'Pêra'. Estudos anteriores como o de Brlansky et al. (6) que utilizaram ramos abordaram caneluras já formadas, mas devido às dimensões da peça, torna-se difícil acompanhar a sua ontogênese, pois é praticamente impossível prever o sítio de origem das caneluras. No presente caso era possível visualizar toda secção transversal do pedúnculo e localizar os sítios onde as alterações estavam ocorrendo.

Estudos prévios de alterações anatômicas causadas pelo CTV concentraram-se na região do enxerto em combinações de laranjeira doce em porta-enxerto intolerante como a laranjeira azeda $(16,21,22$, 23). No geral os autores descrevem alterações significativas no floema, com hipertrofia, hiperplasia, necrose e colapso dos vasos do floema. Atividade anormal no câmbio resulta em saliências. Nos estudos feitos 


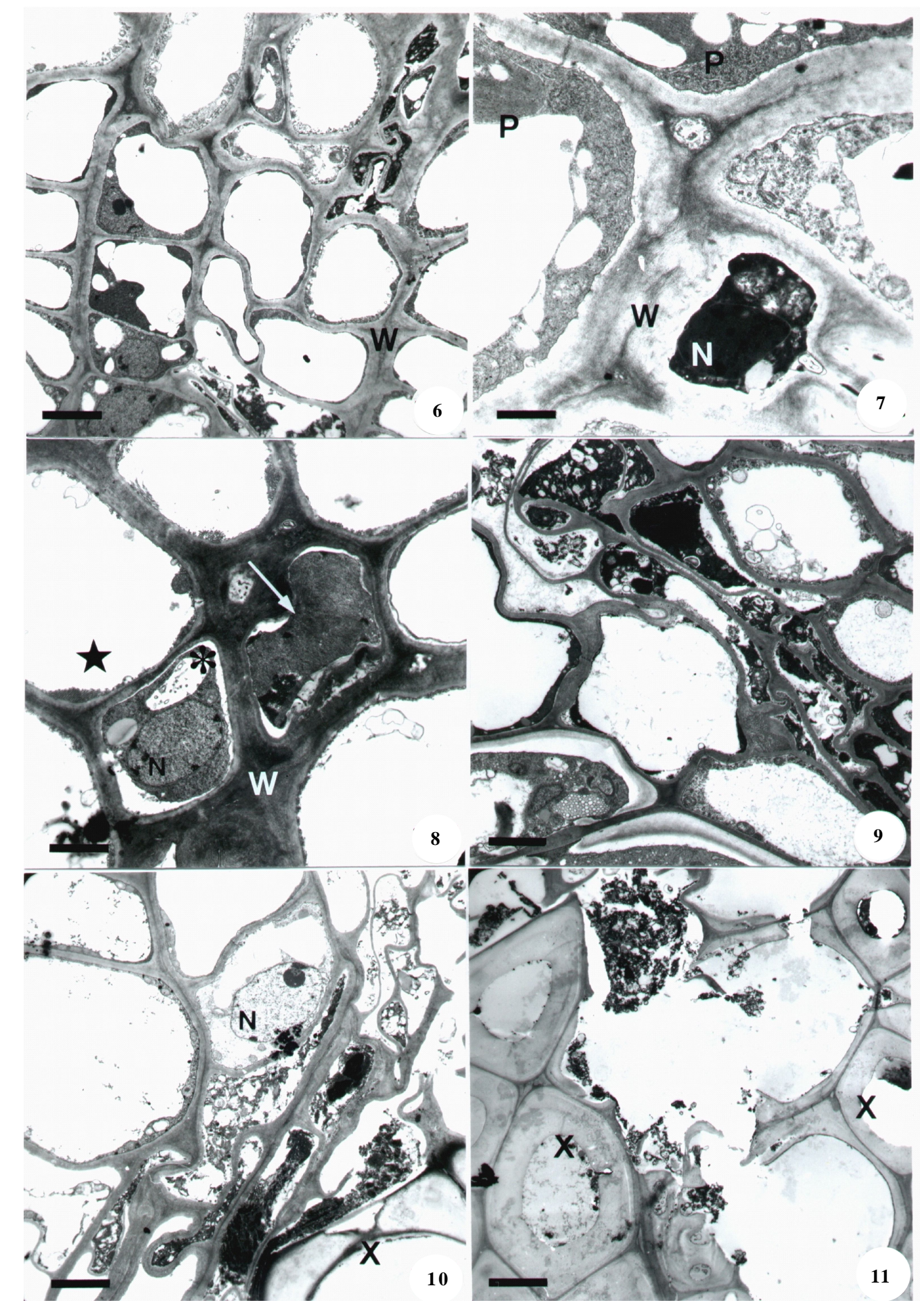

Figuras 6-11. Micrografias eletrônicas de transmissão: detalhes ultraestruturais do processo de formação das caneluras, em pedúnculos florais e de frutos de laranja 'Pera' infectada pelo isolado Capão Bonito do CTV. 6. Parte do câmbio e floema adjacente. Escurecimento de células cambiais (*) e a necrose e colapso de células do floema (seta) (barra $=8,25 \mathrm{~mm}$ ). 7. Detalhe de uma célula companheira adensada, provavelmente precedendo seu colapso (barra $=2 \mathrm{~mm}$ ). 8. Célula companheira adensada, contendo massa de partículas fibrosas, presumivelmente de CTV, e que corresponderia à célula cromática. Ao lado, um elemento do vaso do floema (*) (barra $=3,6 \mathrm{~mm}$ ). 9 e 10 . Células cambiais de conteúdo adensado e rico em vesículas $($ barras $=5,6 \mathrm{~mm}$ e $8,2 \mathrm{~mm}$ ). 11. Detalhe do colapso dos elementos do xilema, vizinhos à zona invadida pela hiperplasia do floema e câmbio, avançando em direção ao xilema secundário (barra $=8,2 \mathrm{~mm}$ ). $\mathrm{N}$ - núcleo; $\mathrm{W}$ - parede celular; $\mathrm{X}$ - elementos de vaso. 
por Brlansky et al. (6) que analisou caneluras causadas por uma estirpe severa australiana de CTV em ramos da laranjeira doce cv. 'Navel' relata também atividade anormal do câmbio adjacente ao floema, gerando uma proliferação tissular que invade e destrói o xilema subjacente, provavelmente pela falta de formação de tecidos normais do xilema, criando as depressões (caneluras) no lenho, evidentes quando se remove a casca do ramo.

As observações realizadas no modelo do pedúnculo de flor/fruto confirmam as observações feitas por Brlansky et al. (6) e acrescenta o fator temporal, permitindo seguir seqüencialmente o processo da gênese das caneluras, na laranjeira doce cv. 'Pêra', infetada pela estirpe severa Capão Bonito, do CTV.

O processo inicia-se com alterações localizadas no floema adjacente ao câmbio. Ocorre uma proliferação e hipertrofia do floema que leva ao colapso e necrose da área. Aparentemente a formação do xilema nesta região do câmbio fica comprometida. Resulta na formação de uma massa parenquimatosa do floema que penetra no lenho, destruindo os vasos e parênquima do xilema e do elemento de vaso mal formados e que resulta nas caneluras. Exame das áreas correspondentes ao microscópio eletrônico de transmissão mostrou detalhes do processo degenerativo do floema e xilema e a presença do CTV nas células companheiras dos vasos crivados. A hiperatividade do câmbio que resulta na proliferação anormal do parênquima do floema e conseqüente invasão do xilema possivelmente represente um processo compensatório da planta, para procurar manter o fluxo de fotossintetato, regenerando o floema infectado pelo CTV e garantindo sobrevida, ainda que limitada, à planta infectada.

$\mathrm{O}$ adensamento celular notado no processo degenerativo do floema observado neste processo resultante da infecção pelo CTV e outros patógenos, dever-se-ia ao acúmulo de compostos fenólicos presentes no vacúolo que invadem o citoplasma. Da forma de glicosídeos no vacúolo, os compostos fenólicos se oxidam pela ação da fenolase e escurecem ao se polimerizarem (18). Este adensamento, associado à degeneração celular, contudo, difere das chamadas células cromáticas descritas por Schneider et al. (23), que corresponderiam às células companheiras que acumulam o CTV. Este fato foi observado no presente trabalho em que muitas células companheiras dos vasos crivados, adensados, continham massas de vírions, como previamente descrito $(9,12,25)$.

Os fatores que levam a estas alterações no floema e câmbio não são conhecidos. Como deveria ocorrer uma infecção sistêmica pelo CTV no floema, esperar-se-ia que as alterações deveriam ser generalizadas e não pontuais. Uma possível explanação seria decorrente do fato de que numa planta infetada pelo CTV ocorrer uma mescla de vários haplótipos, com a prevalência de alguns deles. Durante o processo de disseminação do vírus na planta, algumas áreas seriam infetadas por haplótipos mais agressivos que acarretariam uma destruição e alterações mais significativas, resultando nas caneluras. As regiões adjacentes poderiam se infetar com haplótipos menos severos que apesar da infecção não resultariam em alterações anatômicas significativas.

\section{REFERÊNCIAS BIBLIOGRÁFICAS}

1. Bennet, C. W.; Costa, A. S. Tristeza disease of citrus. Journal of Agricicultural Research, Washington, v.78, p.207-237, 1949.

2. Bitancourt, A. A. A podridão das radicelas dos Citros na província de Corrientes, Argentina. O Biológico, São Paulo, n.6, p.85 288, 1940a.
3. Bitancourt, A. A. A podridão das radicelas dos Citros na província de Corrientes, Argentina. O Biológico, São Paulo, n. 6, p.356 $364,1940 \mathrm{~b}$

4. Bitancourt, A. A. A podridão das radicelas dos Citros na província de Corrientes, Argentina. O Biológico, São Paulo, n. 8, p.62 69, 1942.

5. Bar-Joseph, M.; Murant A. F. Closterovirus group. In:Murant, A. F.; Harrison, B. D. Descriptions of plant viruses. Commonwealth Mycological Institute and Association of Applied Biologists. Dundee, Scotland, v.16, n. 260, 1982.

6. Brlansky, R. H. Histology of sweet orange stem pitting caused by an Australian isolate of Citrus Tristeza Virus. Plant Disease, St. Paul, v.86, n.10, p.1169-1174, 2002.

7. Fawcett, H. S.; Wallace, J. M. Evidence of the virus nature of citrus and quick decline. The California Citrograph, Los Angeles, n. 32, p. 88-89, 1946.

8. Feder, N.; O’Brien, T. P. Plant microtechinique: some principles and new methods. American Journal of Botany, St. Louis, v.55, n.1, p.123-142, 1968.

9. Gowda, S., Satyanarayana, T., Davis, C.L., Navas-Castillo, J., Albiach-Marti, M.R., Mawassi, M., Valkov, N., Bar-Joseph, M., Moreno, P.; Dawson, W. The p20 gene product of Citrus tristeza virus accumulates in the amorphous inclusion bodies. Virology, New York, v.274, p. 246-254, 2000.

10. Karnovsky, M. J. A formaldehyde-glutaraldehyde fixative of high osmolality for use in eletron microscopy. Journal of Cellular Biology, New York, n.27, p.137-138, 1965.

11. Kitajima, E. W.; Silva, D. M.; Oliveira, A. R.; Müller, G. W.; Costa, A. S. Thread-like particles associated with tristeza disease of citrus. Nature, New York, v.201, n.4923, p.1011 - 1012, 1964.

12. Kitajma, E. W.; Costa, A. S. Electron microscopy of the citrus tristeza virus in citrus leaf tissues. In:Proceedings of the $46^{\text {th }}$ Conference of International Organization of Citrus Virologists (JF Childs, ed.). Gainesville, Univ.Florida Press, p.59-64, 1968.

13. Kitajima, E. W.; Nome, C. Microscopia eletrónica en virologia vegeal. In Do Campo, D. \& Lenardon, S. eds. Métodos para detectar patógenos sistémicos. Córdoba, IFFIVE/INTA, p.5987, 1999

14. Meneghini, M. Sobre a natureza da transmissibilidade da doença "tristeza" dos citros. O Biológico, São Paulo, n.12, p.285 287, 1946.

15. Meneghini, M. Experiências de transmissão da doença "tristeza" dos citros pelo pulgão preto da laranjeira. O Biológico, São Paulo, n.14, p.115 - 118, 1948.

16. Mosse, B. Graft incompatibility in fruit trees. Technical Communications $n^{\circ}$ 28. Common Wealth Bureau of Horticulture and Plantation Crops. East Maling, Maidstone, Kent, England. 36p., 1952.

17. Müller, G. W., Targon, M. L. P. N., Carvalho, S. A., Souza, A. A.; Rodrigues, J. C. V. Doenças de citros causadas por vírus e viróides. In Mattos Jr., D., De Negri, J. D., Pio, R. M., Pompeu, J. (eds.) Citros. Campinas, Instituto Agronômico e Fundag. p.569-604, 2005.

18. Roshchina, V. V.; Roshchina, V. D. The excretory Function of Higher Plants. Heidelberg, Germany, Springer-Verlag. 314p., 1993.

19. Rubio, L., Ayllon, M. A., Kong, P., Fernandez, A., Polek, M.A., Gerri, J., Moreno, P.; Falk, B. W. Genetic variation of Citrus tristeza virus isolates from California and Spain: evidence for mixed infection and recombination. Journal of Virology. Philadelphia, n.75, p.8054-8062, 2001.

20. Ruetze, M.; Schmitt, V. Glykol-metacrylat (GMA) als einbettungssystem is histologische untersuchungen von koniferen. NadeIn European Journal Pathology, Berlin, n.16, p.21-324, 1986.

21. Schneider, H.; Fawcett, H. S. A progress report on quick decline studies. The California Citrograph, Los Angeles, n.31, p.198$199,1946$.

22. Schneider, H.; Bitancourt, A. A.; Rossetti, V. Similarities in the pathological anatomy of Quick-Decline and Tristeza-diseased 
orange trees. Phytopathology, St. Paul, n.37, p.845-846, 1947.

23. Schneider, H.; Wallace, J. M.; Dimitman, J. E. The pathological anatomy of bud-union tissues of orange trees and its value in the diagnosis of quick decline. Phytopathology, St. Paul, n.40, p.24, 1950 .

24. Schneider, H. The anatomy of tristeza-virus-infected citrus Citrus Virus Diseases. Gainesville, University of California, Division of Agricultural Science, Paper n.1104, p.73-84, 1959.

25. Schneider, H.; Sasaki, P. J. Ultrstructural studies of chromatic cells in tristeza-diseased lime. Proceedings of the $5^{\text {th }}$ Conference of International Organization of Citrus Virologists, Gainesville, Univ.Florida Press, p. 222-228, 1972.

26. van regenmortel, M. H. V.; Fauquet, C. M.; Bishop, D. H. L.; Carstens, E. B.; Estes, M. K.; Lemon, S. M.; Maniloff, J.; Mayo, M. A.; Mcgeoch, D. J.; Pringle, C. R.; Wickner, R. B. Virus Taxonomy Seventh Report of the International Committee on Taxonomy of Viruses Academic Press, United States of America. 1162 p., 2000. 